\title{
EcoRI Restriction Endonuclease Cleavage Site Map of Bacteriophage P22 DNA
}

\author{
Ethel Noland Jackson, Harvey I. Miller and Mark L. Adays \\ Department of Microbiology, The University of Michigan Medical School \\ Ann Arbor, Mich. 48109, U.S.A.
}

(Received 18 May 1977, and in revised form 9 September 1977)

\begin{abstract}
'The seven EcoRI restriction endonuclease cleavage sites in bacteriophage P22 DNA have been mapped. The cleavage site map of circularly permuted P22 linear DNA is a circle. The positions of EcoRI sites in the early region of the P22 genome were determined by comparing products of EcoRI digestion of mature linear P22 chromosomes with the EcoRI cleavage fragments of DNA of three גimmP22 hybrid phages and a P22 deletion mutant. An EcoRI site in the late region was mapped by partial digestion of the P22 deletion mutant DNA. Sinee the $\mathrm{P} 22$ genes included in the $\lambda i m m \mathrm{P} 22$ hybrid phages, and the genetic region missing in the P22 deletion mutant are known, some $\mathrm{P} 22$ genes can be positioned on this initial physical map of the P22 genome relative to EcoRI cleavage sites.
\end{abstract}

\section{Introduction}

P22 linear DNA molecules are a limited set of circular permutations of the bacteriophage genome (Rhoades et al., 1968; Tye et al., 1974a,b). Restriction endonuclease digestion of these permuted chromosomes produces a unique set of fragments bounded by two restriction enzyme cleavage sites plus an assortment of fragments bounded by a chromosome end and a single restriction site. In order to locate the sites at which the restriction endonuclease $E c o$ RI cleaves P22 DNA, we have determined which fragments are produced by $E c o R I$ cleavage at both ends, and which fragments are created when the end of a permuted chromosome falls between two EcoRI sites, and we have mapped these fragments on the P22 genome. In this paper, EcoRI digestion products of the permuted P22 linear chromosomes are characterized, and the P22 EcoRI cleavage sites present in P22 substitutions in non-permuted chromosomes are mapped. In the following paper (Jackson et al., 1978) the fragments produced by $E c o$ RI cleavage of permuted ends of P22 chromosomes are analyzed.

In these experiments, P22 EcoRI sites are mapped in bacteriophage $\lambda$ chromosomes carrying substitutions of P22 early genes. Since the P22 sequences are embedded in a DNA molecule which has the unique, non-permuted ends of the $\lambda$ parent, the P22 fragments generated by $E c o R I$ cleavage are not altered by permuted molecular ends. From EcoRI cleavage site maps of three hybrid chromosomes, a partial EcoRI cleavage site map of P22 DNA can be derived. Since the P22 genes included in each hybrid are known, the P22 EcoRI cleavage site map can be oriented with the genetic map. We report here the size and order of EcoRI fragments of the P22 chromosome, and the assignment of some P22 genes to particular fragments. 


\section{Materials and Methods}

(a) Phage and bacteria

P22 c1-7 was obtained from M. Levine and used as the source of wild-type P22 DNA. P22 bpl and P22 bp5, two non-defective, plaque-forming deletion mutants, were obtained from D. Botstein (Tye et al., 1974a). The P22 bp5 mutant used carried amber mutations in genes $c 2$ and 13.

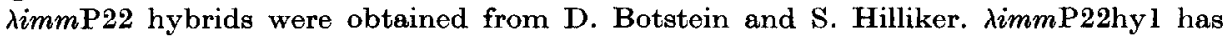
been described in detail by Botstein \& Herskowitz (1974). It carries P22 genes 24, c2-ts30, 18,12 in place of $\lambda$ genes $N, c \mathrm{I}, O, P$. The $\mathrm{P} 22$ substitution in $\lambda$ imm $\mathrm{P} 22 \mathrm{hy} 38 \mathrm{c2-5} 13^{-} \mathrm{amH} 10 \mathrm{l}$ has been shown to include at least P22 genes 24,c2.5 (a clear mutation), 18, 12, and 13-amH101 (a lysis defective mutation) (S. Hilliker, personal communication). The P22 substitution in גimmP22hy37 includes at least P22 genes 24,c2-5, 18, 12 (S. Hilliker, personal communication). It has a $s p i^{-}$phenotype (S. Hilliker, personal communication; Zissler et al., 1971).

The lyosgen Escherichia coli W3102 gal $^{-}{ }^{-}$str $^{\mathfrak{R}}$ ( $\lambda c I 857$ S7) was obtained from D. Friedman.

\section{(b) Phage lysates}

All P22 lysates were grown by infection of Salmonella typhimurium strain 18, a derivative of LT2 obtained from M. Levine. Cells were grown in L broth ( $1 \%$ Bacto-tryptone, $0.5 \%$ yeast extract (Difco), $0.5 \% \mathrm{NaCl}, 0.1 \%$ glucose) at $37^{\circ} \mathrm{C}$ with aeration to $2 \times 10^{8}$ to $3 \times 10^{\mathrm{g}}$ cells $/ \mathrm{ml}$. Phage were added to a multiplicity of infection of 1 to 5 , and incubation at $37^{\circ} \mathrm{C}$ with shaking was continued until lysis, or until about $2.5 \mathrm{~h}$ after infection when the infecting phage carried the lysis-defective $13^{-}$allele. The culture was then treated with chloroform to complete lysis.

$\lambda c I 857 \mathrm{~S} 7$ and $\lambda i m m \mathrm{P} 22$ hy $1 c 2-t s 30$ lysates were grown by induction. The temperaturesensitive lysogen W3102 $\mathrm{str}^{\mathrm{R}} \mathrm{gal}^{-}(\lambda \mathrm{CI857} \mathrm{S} 7)$ was grown in $\mathrm{L}$ broth at $32^{\circ} \mathrm{C}$ with aeration to $4.5 \times 10^{8}$ cells $/ \mathrm{ml}$, heated to $45^{\circ} \mathrm{C}$ for $5 \mathrm{~min}$, and growth continued at $37^{\circ} \mathrm{C}$ with vigorous aeration for $3 \mathrm{~h}$ after induction. Cells were lysed with chloroform. The heat-inducible lysogen C600(AimmP22hyl c2-ts30) was grown with shaking in L broth to $2 \times 10^{8}$ to $3 \times 10^{8} \mathrm{cells} / \mathrm{ml}$ at $30^{\circ} \mathrm{C}$, then shifted to $40^{\circ} \mathrm{C}$ and aerated for $90 \mathrm{~min}$. Chloroform was added to complete lysis.

$\lambda i m m \mathrm{P} 22 \mathrm{hy} 37$ and $\lambda i m m \mathrm{P} 22 \mathrm{hy} 38$ were grown by infection of $E$. coli strain C600. Cells were grown at $37^{\circ} \mathrm{C}$ in tryptone broth $(1 \%$ Bacto-tryptone (Difco), $0.5 \% \mathrm{NaCl}$ ) supplemented with $1 \mathrm{mg}$ maltose $/ \mathrm{ml}$ and $10^{-2} \mathrm{M}-\mathrm{MgCl}_{2}$ to a density of $2 \times 10^{8}$ to $3 \times 10^{8} \mathrm{cells} / \mathrm{ml}$, when phage were added at a multiplicity of infection of 1 . After shaking at $37^{\circ} \mathrm{C}$ for $2 \mathrm{~h}$ after infection, chloroform was added to complete lysis.

\section{(c) Phage DNA preparations}

Bacterial debris was removed from the lysates by centrifugation at $9000 \mathrm{revs} / \mathrm{min}$ for $10 \mathrm{~min}$ in a JA20 rotor in the Beckman J2I centrifuge. The lysates were concentrated by precipitation following addition of $140 \mathrm{~g}$ polyethylene glycol 6000/1 (J. T. Baker Chemical Co.) and $40 \mathrm{~g} \mathrm{NaCl} / \mathrm{l}$. After the mixture was stored overnight at $4^{\circ} \mathrm{C}$, the precipitate was collected by centrifugation at $10,000 \mathrm{revs} / \mathrm{min}$ in the JA20 rotor for $30 \mathrm{~min}$. The precipitate was resuspended in $10 \mathrm{~mm}$-Tris $\cdot \mathrm{HCl}(\mathrm{pH} \mathrm{7.5)}(\mathrm{P} 22)$ or $10 \mathrm{~mm}$-Tris $\cdot \mathrm{HCl}(\mathrm{pH} 7 \cdot 5)$, $10 \mathrm{mM}_{-} \mathrm{MgSO}_{4}(\lambda)$. The phage suspension was centrifuged twice at $10,000 \mathrm{revs} / \mathrm{min}$ in the JA20 rotor in the Beckman J21 centrifuge to remove cell debris. CsCl was then added to the lysates to $4.0 \mathrm{~m}$ (density 1.5 ) and the phage were purified by banding them twice in CsCl gradients (centrifugation at $37,000 \mathrm{revs} / \mathrm{min}$ for $12 \mathrm{~h}$ in a Beckman type 65 rotor at $20^{\circ} \mathrm{C}$ ). After the second banding, the phage were collected and dialyzed against the resuspension buffers given above. Phage were extracted 3 times with phenol (Mallinkrodt) which had been washed 3 times with $10 \mathrm{mM}$-Tris $\cdot \mathrm{HCl}(\mathrm{pH} \mathrm{7.5}), 10 \mathrm{~mm}$-EDTA, $0 \cdot 3 \mathrm{M}-\mathrm{NaCl}$, followed by 3 washes with 10 mm-Tris $\cdot \mathrm{HCl}(\mathrm{pH} 7.5), 1$ mM-EDTA. The DNA was dialyzed against $10 \mathrm{~mm}$-Tris $\cdot \mathrm{HCl}$ (pH 7.5), 1 mM-EDTA, $10 \mathrm{~mm} \cdot \mathrm{NaCl}$. 


\section{(d) EcoRI endonuclease cleavage}

EndoR $\cdot E c o R I$ was purified according to the method of Thomas \& Davis (1975). It was shown to be free of contaminating endonuclease activity when assayed under the reaction conditions described below.

A total of 0.35 to $0.7 \mu \mathrm{g}$ P22 or $\lambda$ DNA was cleaved with $1 \mu$ of $E c o R I$ endonuclease in a reaction volume of $30 \mu \mathrm{l}$. Reactions were carried out in $100 \mathrm{~mm}$-Tris $\cdot \mathrm{HCl}(\mathrm{pH} 7 \cdot 5)$. $50 \mathrm{mM}-\mathrm{NaCl}, 5 \mathrm{~mm}-\mathrm{MgCl}_{2}$ at $37^{\circ} \mathrm{C}$ for $30 \mathrm{~min}$, and then terminated by addition of $3 \mu \mathrm{l}$ of $75 \%$ sucrose $(\mathrm{w} / \mathrm{v}), 0.05 \%$ bromophenol blue, $0.1 \mathrm{M}$-EDTA.

\section{(e) Agarose gel electrophoresis}

Gels were prepared from a $0.7 \%(\mathrm{w} / \mathrm{v})$ solution of agarose (SeaKem) in electrophoresis buffer (40 mM-Tris $\cdot \mathrm{HCl}, 1 \mathrm{mM}$-EDTA, $5 \mathrm{~mm}$-sodium acetate $(\mathrm{pH} 8 \cdot 2))$. The solution was prepared by autoclaving for $15 \mathrm{~min}$, then cooling to 50 to $60^{\circ} \mathrm{C}$ before pouring gels. Gels $(15 \mathrm{~cm} \times 0.6 \mathrm{~cm})$ were poured at room temperature into $16-\mathrm{cm}$ glass tubes. The bottoms of the glass tubes were sealed with Parafilm. After the gels solidified, the tops of the tubes were covered with nylon mesh held in place by an O-ring, and the tubes inverted so that the flat surface of the gel formed against the Parafilm became the top of the gel.

DNA samples were made $7.5 \%$ in sucrose and layered under buffer onto the tops of the gels. Just before layering, samples were heated for $10 \mathrm{~min}$ at $70^{\circ} \mathrm{C}$ to disrupt hydrogenbonding between short cohesive ends. Samples contained 0.3 to $0.7 \mu \mathrm{g}$ DNA in $30 \mu \mathrm{l}$. Following an initial period of $2.5 \mathrm{~min}$ when samples were run into the gels at $100 \mathrm{~V}$, electrophoresis was performed at $2 \mathrm{~mA} / \mathrm{gel}$ for $4 \mathrm{~h}$ at room temperature. DNA bands were visualized following electrophoresis by removing the gels from the glass tubes and staining them for $20 \mathrm{~min}$ in $1 \mu \mathrm{g}$ ethidium bromide/ $\mathrm{ml}$ in electrophoresis buffer. The bands were viewed by fluorescence of the bound ethidium bromide when the gels were placed over a u.v. light source (transilluminator model C-50, Ultraviolet Products, Ine.). The gels were photographed with a Polaroid MP-3 Land Camera using a no. 23A Wratten gelatin filter and a u.v. filter (Ultraviolet Products).

\section{(f) Electron microscopy}

DNA was mounted for electron microscopy by the aqueous technique described by Davis et al. (1971), using simian virus 40 (SV40) form II (open circular) DNA added to each sample as an internal length standard. The molecular weight of SV40 DNA was taken as $3.40 \times 10^{6}$. Samples were rotary shadowed with $\mathrm{Pt} / \mathrm{Pd}$ and were photographed in a Philips EM300 electron microscope. The projected images of the molecules were traced on paper and measured with a map measurer.

\section{(g) Nomenclature}

We have used as far as possible the conventions suggested by Smith \& Nathans (1973) for naming DNA fragments generated by EcoRI cleavage. Some additions to their conventions are required by the hybrid and deletion phages used in this work. The 8 bands that result from electrophoresis of an EcoRI digest of P22 wild-type DNA in $0.7 \%$ agarose gels are assigned letters in order of increasing electrophoretic mobility and decreasing fragment size (Fig. $1(a)$ ). Therefore, the band migrating most slowly is designated P22 EcoRI A. When one of these P22 wild-type fragments appears in the EcoRI digest of a P22 deletion mutant, the letter designation for that fragment is the same as in the P22 parent. For example, the third band from the top of the P22 bp5 gel (Fig. 5(a)) is designated P22 EcoRI D, since it is identical to wild-type P22 EcoRI D, the fourth band in a wildtype digest. Bands which appear in the EcoRI digest of a P22 mutant but not in the P22 parent are assigned Greek letters in order of increasing electrophoretic mobility, for example, P22bp5 $E$ coRI $\alpha . E c o R I$ fragments of $\lambda i m m P 22$ hybrid phage DNA are named by the same convention used for P22 deletion mutants. If a $\lambda$ or P22 wild-type fragment appears in the hybrid digest, it retains the same letter designation as in the P22 or $\lambda$ parent. Bands found in the hybrid but not in either parent are assigned Greek letters, e.g. dimmP22hyl EcoRI $\alpha$. The $\lambda$ fragments are lettered here according to map order, not size, in accordance with the map given by Thomas \& Davis (1975). EcoRI cleavage sites 
in P22 DNA are assigned Arabic numerals in order of map position, with numbering beginning at the cleavage site nearest the genetic site where P22 DNA packaging begins, and proceeding counterclockwise around the circular fragment map (Fig. 6). P22 and $\lambda$ $E c o R I$ cleavage sites retained in phages derived from these parents bear the same number designation as in the parent.

\section{Results}

(a) EcoRI endonuclease fragments of $P 22 D N A$

P22 linear DNA molecules were extracted from phage particles and cleaved with endonuclease R.EcoRI (Hedgpeth et al., 1972). The cleavage products from complete digestion of P22 DNA were separated by electrophoresis through an agarose gel, stained with ethidium bromide, and viewed by fluorescence of the bound dye in u.v. light. Eight bands are seen (Fig. 1(a); Helling et al., 1974).

Two of the eight bands resulting from $E c o$ RI cleavage of P22 DNA appear unusual upon inspection of the gel. Running slightly faster than band $A$ and not resolved from it is a diffuse band, indicating DNA fragments which are heterogeneous in molecular weight. In addition, band $\mathrm{D}$ stains less intensely than band $\mathrm{E}$ and therefore is present in lower yield than band $\mathrm{E}$. These anomalies do not result from incomplete cleavage, since they persist when a fourfold higher enzyme concentration is used. In the accompanying paper, we show that these features are consequences of the circularly permuted linear form of the P22 DNA substrate. Both band D and the heterogeneous smaller fragments in band A are segments of fragment A produced by EcoRI cleavage of ends of permuted molccules (Jackson et al., 1978).

\section{(b) Molecular weights}

The molecular weights of P22 EcoRI fragments B through $\mathrm{H}$ shown in Table 1 were determined by measuring under standard conditions the electrophoretic mobility of each band relative to bacteriophage $\lambda E c o R I$ fragment D present in the same gel. Relative mobility is related to molecular weight by the standard curve shown in Figure 2. The standard curve was obtained by plotting the logarithm of the molecular weight versus the electrophoretic mobility relative to bacteriophage $\lambda E c o R I$ fragment $\mathrm{D}$ for DNA molecules of known molecular weight. Under these conditions, the change in relative mobility as a function of $\log$ molecular weight is quite small for DNA fragments of molecular weight greater than about $10 \times 10^{6}$. Thus in this molecular weight range, determinations of molecular weight based on electrophoretic mobility will be inaccurate. Since the molecular weight of fragment A estimated from the electrophoretic mobility measurements is $12.5 \times 10^{6}$, a more accurate estimate of the molecular weight was obtained by measuring the length of fragment $A$ in the electron microscope relative to an SV40 DNA standard. Fragment A was obtained from a P22 deletion mutant (P22bpl) in which the position of molecular ends generated during DNA maturation is altered with respect to the P22 map such that fragment $A$ is intact in this mutant (Jackson et al., 1978). Figure 3(a) is a histogram of length measurements of intact fragment A from P22bpl. For comparison, the histogram of fragment A lengths of P22 wild-type is shown in Figure 3(b). The latter histogram includes the heterogeneous smaller derivatives of fragment A produced by EcoRI cleavage of molecular ends located within fragment A in P22 wild-type. The longer molecules in the P22 histogram correspond to the intact fragment A of the P22bpl histogram. The value of $(12.96 \pm 0 \cdot 61) \times 10^{6}$ given as the molecular 


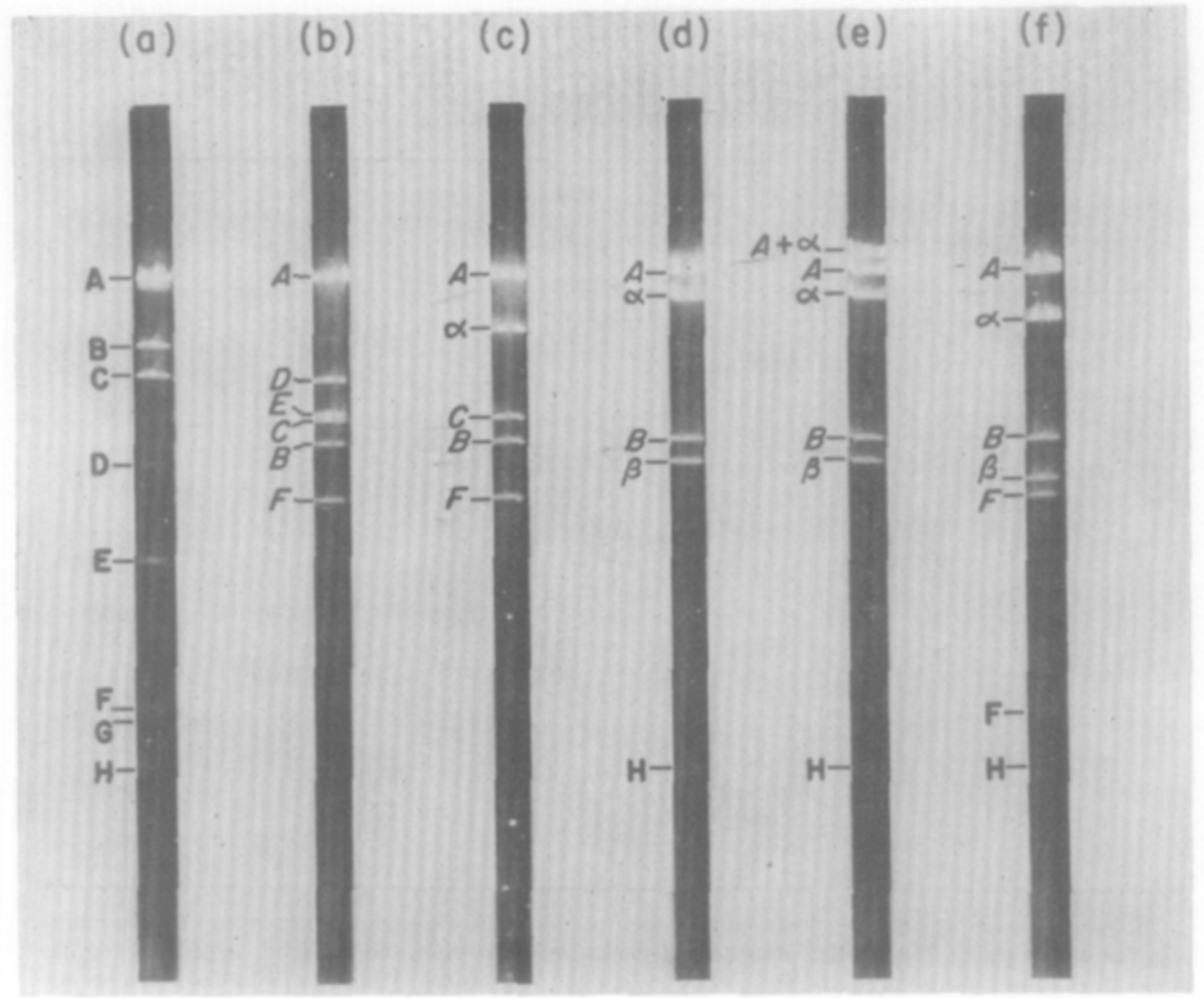

Fia. 1. Agarose gel electrophoresis of EcoRI endonuclease eleavage products of P22, $\lambda$ or

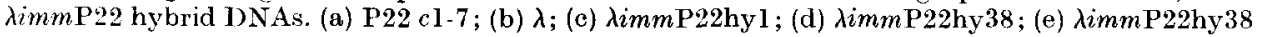
showing dimer (fragments $A+\alpha$ ) formed by hydrogen-bonds between $\lambda$ cohesive ends; (f) $\operatorname{\lambda immP22hy37.~}$

Agarose gel electrophoresis was performed and the gels stained and photogruphed as described in Materials and Methods. The EcoRI digest in gel (e) was not heated to $70^{\circ} \mathrm{C}$ before layering on the gel.

P22 hands are labeled by capital letters in nrder of increasing electrophoretic mobility. $\lambda$ bands are labeled (italic letters) according to fragment map order (Thomas \& Davis, 1975). Bands appearing in an EcoRI digest of a $\lambda i m m P 22$ hybrid which are different from any P22 or $\lambda$ band are designated by Greek letters (see Materials and Methods for description of nomenclature conventions).

weight of fragment $A$ in Table 1 was determined for fragment $A$ of P22 bpl from the data shown in Figure 3(a).

The sum of the molecular weights of the EcoRI fragments which have EcoRI termini at both ends, A, B, C, E, F, G and H, is in good agreement with the value predicted from the molecular weight of the intact P22 DNA molecule. (Note that fragment $D$ and the fragments of heterogeneous size which run slightly faster than fragment $A$ are all derivatives of fragment $A$ and so are not included in the summation of molecular weights. See the accompanying paper (Jackson et al., 1978) for a detailed explanation.) A molecular weight of $(28.50 \pm 1.07) \times 10^{6}$ was calculated for P22 from electron microscopic length measurements made under the same conditions and 
Table 1

Molecular weights of EcoRI fragments of P22, $\lambda$, and $\lambda \mathrm{imm} P 22$ bacteriophage DNA molecules

\begin{tabular}{|c|c|c|c|c|c|c|}
\hline \multirow{3}{*}{$\begin{array}{l}\text { P22 EcoRI } \\
\text { fragments }\end{array}$} & \multirow{3}{*}{$\begin{array}{c}\lambda E c o R I \\
\text { fragments }\end{array}$} & \multicolumn{5}{|c|}{ Molecular weight $\left(\times 10^{-6}\right)$} \\
\hline & & & & $\lambda i m m \mathrm{P} 22$ & $\lambda i m m \mathrm{P} 22$ & $\lambda i m m \mathrm{P} 22$ \\
\hline & & $\mathbf{P} 22$ & $\lambda$ & hyl & $h_{y} 38$ & hy 37 \\
\hline & $A$ & & $13 \cdot 7$ & $13 \cdot 7$ & $13 \cdot 7$ & $13 \cdot 7$ \\
\hline \multirow[t]{4}{*}{$A$} & & $12 \cdot 96$ & & & & \\
\hline & & & & & $\alpha \quad 9 \cdot 8$ & \\
\hline & & & & & & $\alpha \mathbf{7 \cdot 6}$ \\
\hline & & & & $\alpha 7 \cdot 15$ & & \\
\hline $\mathrm{B}$ & & $6 \cdot 10$ & & & & \\
\hline \multirow{5}{*}{$\mathrm{C}$} & & $4 \cdot 77$ & & & & \\
\hline & $D$ & & $4 \cdot 74$ & & & \\
\hline & $E$ & & $3 \cdot 73$ & & & \\
\hline & $\bar{C}$ & & $3 \cdot 48$ & $3 \cdot 48$ & & \\
\hline & $B$ & & $3 \cdot 02$ & 3.02 & $3 \cdot 02$ & 3.02 \\
\hline \multirow[t]{4}{*}{$\mathrm{D}$} & & $2 \cdot 65$ & & & & \\
\hline & & & & & $\beta \mathbf{2 . 6 5}$ & \\
\hline & & & & & & $\beta 2 \cdot 4$ \\
\hline & $F$ & & $2 \cdot 13$ & $2 \cdot 13$ & & $2 \cdot 13$ \\
\hline $\mathrm{E}^{\mathrm{3}}$ & & $1 \cdot 59$ & & & & \\
\hline $\mathrm{F}$ & & $0 \cdot 75$ & & & & $0 \cdot 75$ \\
\hline $\mathrm{G}$ & & $0 \cdot 72$ & & & & \\
\hline $\mathrm{H}$ & & 0.56 & & & $0 \cdot 56$ & 0.56 \\
\hline
\end{tabular}

Molecular weights of EcoRI fragments of each phage DNA are given in the order the fragments appear in the gel in Fig. 1. P22 fragment designations and molecular weights appear in regular type. $\lambda$ fragment names and molecular weights are given in italics. Molecular weights of fragments unique to a dimm 22 hybrid are shown in bold face type.

The molecular weight of P22 fragment A was obtained from electron microscopic measurements of the length of A from P22 deletion mutant bpl (Fig. 3(a)).

Molecular weights of $\mathrm{P} 22$ fragments $\mathrm{B}$ to $\mathrm{H}$ and all fragments unique to $\lambda \mathrm{imm} \mathrm{P} 22$ hybrids were obtained by measuring the electrophoretic mobility of the fragment in agarose gels relative to the position of $\lambda E c o R I D$ in the same gel and then using the standard eurve in Fig. 2 which relates relative mobility to molecular weight. Molecular weights of $\mathrm{P} 22$ fragments $\mathrm{B}$ to $\mathrm{H}$ are the mean values from 9 gels. Molecular weights of each new hybrid fragment are the means from 5 or more gels.

using the same SV40 standard DNA as was used for length measurements of fragment A (27 P22 DNA molecules measured). This is close to the values of $(28 \pm 0.9) \times 10^{6}$ (Tye et al., 1974a) and $26 \times 10^{6}$ to $27 \times 10^{6}$ (Rhoades et al., 1968) previously reported. P22 linear DNA molecules isolated from phage particles have a terminal redundancy estimated to be 2 to $3 \%$ (Tye, et al., 1974a). Therefore, one set of genes which is complete but not redundant should have a molecular weight of $28.5 \times 10^{6}$ minus $0.86 \times 10^{6}$ (the terminal redundancy), or $27.64 \times 10^{6}$. The sum of molecular weights of fragments A, B, C, E, F, G and $\mathrm{H}$ from Table 1 is $27 \cdot 45 \times 10^{6}$.

The molecular weights of P22 EcoRI fragments have been determined previously by agarose gel electrophoresis as part of a survey of EcoRI digests of 18 viruses (Helling et al., 1974). The values in Table 1 differ from those reported earlier. The sum of the fragment molecular weights in the earlier work (excluding fragment D) is $25.2 \times 10^{6}$, about $10 \%$ lower than the predicted value. We believe the molecular weight determinations reported here to be more accurate. The electron microscopic 


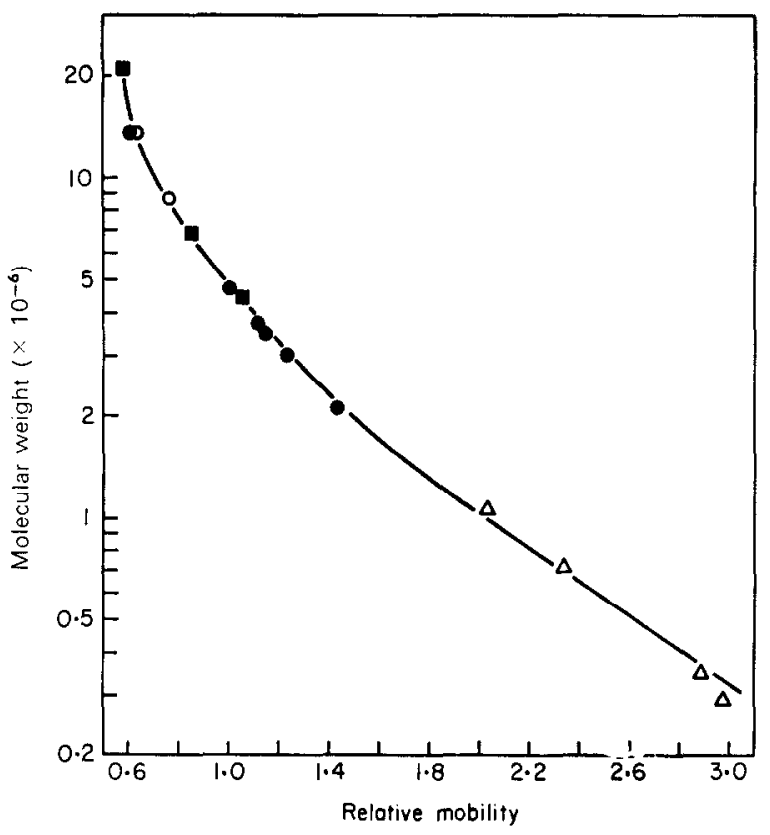

Fig. 2. Relative electrophoretic mobility in $0.7 \%$ agarase gels of DNA molecules of known molecular weights. (O) $\lambda$ EcoRI fragments; (O) $\lambda \mathrm{gt} \cdot \lambda c E c o R I$ fragments; (D) pCC4 EcoRI fragments; $(\triangle)$ SV40 HindIII fragments.

Agarose gel electrophoresis was performed and DNA bands visualized and photographed as described in Materials and Methods. The positions of bands were measured on photographic negatives using a Nikon microcomparator. Mobility is plotted relative to the position of $\lambda$ EcoRI D run in the same gel. Each point represents the mean position from 5 or more gels. The molecular weight values for the DNA molecules used were obtained from the following sources: EcoRI fragments of bacteriophage $\lambda$ DNA, Thomas \& Davis (1975); EcoRI fragments of bacteriophage $\lambda g t \cdot \lambda c$ DNA, Thomas et al. (1974); HindIII fragments of SV40 viral DNA, Lai \& Nathans (1974); EcoRI fragments of plasmid pCC4 DNA, Collins et al. (1976).

determination should give a more accurate measurement of the molecular weight of fragment A. Differences in the molecular weight values for fragments $\mathrm{B}$ and $\mathrm{C}$ may reflect differences in the standard curves used. The standard plot used by the earlier workers lacks reference fragments in the range between $4.7 \times 10^{6}$ and $13.7 \times 10^{6}$, where extrapolation is difficult. The curve in Figure 2 has three points in this range, and therefore should yield better molecular weight approximations. The conditions of electrophoresis used here give sharper bands for fragments of low molecular weight than the longer electrophoresis times used in the earlier study, so the present values for fragments $\mathrm{E}, \mathrm{F}, \mathrm{G}$ and $\mathrm{H}$ should be more precise.

\section{(c) P22 partial fragment order determined by analysis of $\lambda \mathrm{imm} P 22$ hybrids}

A partial map order of P22 EcoRI fragments was determined using information gained from the study of three different $\lambda i m m P 22$ hybrid phages. These viable hybrids have overlapping sets of P22 early genes substituted for analogous $\lambda$ genes (Botstein \& Herskowitz, 1974). The P22 genes present in each hybrid have been determined by genetic methods and the physical length of one of the substitutions has been visualized by heteroduplex analysis (Botstein \& Herskowitz, 1974; S. Hilliker, personal communication). Comparison of EcoRI digestion products of P22, 


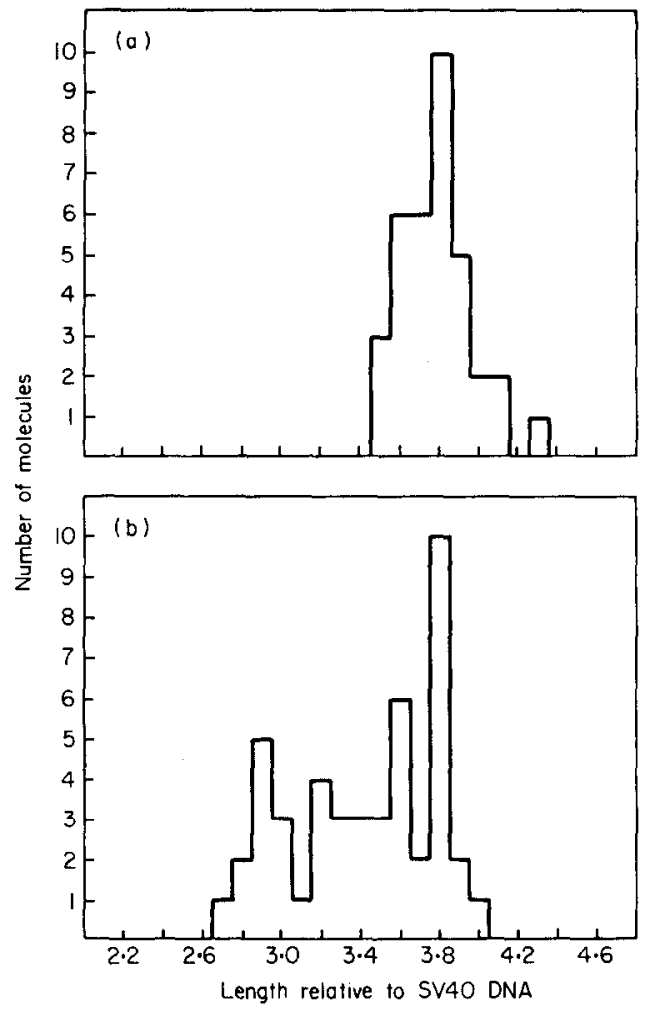

Fig. 3. Histograms of lengths of P22 EcoRI fragment A.

(a) Histogram of the length of P22 fragment A obtained by EcoRI endonuclease cleavage of P22 deletion mutant P22 bpl in which fragment $A$ is not cleaved during DNA packaging. Circular SV40 DNA $\left(M_{\mathrm{r}}=3.4 \times 10^{6}\right)$ was used as calibration on the same grid. Lengths are given relative to the mean length of $40 \mathrm{SV} 40 \mathrm{DNA}$ molecules. Fragment A mean $M_{\mathrm{r}}=(12.96 \pm 0.61) \times 10^{6}$ (34 molecules measured).

(b) Histogram of lengths of P22 fragment A obtained by EcoRI endonuclease cleavage of P22 wild-type DNA in which some molecules are fragments of A produced during DNA packaging. Lengths are given relative to the mean contour length of circular SV40 DNA on the same grid.

$\lambda$ immP22 hybrids and $\lambda$ DNAs established the order of some of the P22 EcoRI fragments. This approach to determining the P22 EcoRI fragment map has several advantages in addition to its simplicity. Use of $\lambda$ imm $\mathrm{P} 22$ hybrids avoids complications in the fragment pattern due to circular permutation of P22 DNA. All the גimmP22 hybrid DNA molecules have unique, non-permuted sequences and $\lambda$ cohesive ends. $E c o \mathrm{RI}$ analysis of the $\lambda i m m \mathrm{P} 22$ hybrid phages also allows assignment of some $\mathrm{P} 22$ genes to particular P22 EcoRI fragments. In some cases, information about the physical location of P22 genes in the hybrids gained from heteroduplex studies (Botstein \& Herskowitz, 1974) allowed us to calculate the physical location of a P22 gene within an $E c o$ RI fragment.

\section{(d) EcoRI fragments of גimm P22hy1}

Botstein \& Herskowitz (1974) showed that hybrid phage גimmP22hyl has the late genes and the att and int genes of phage $\lambda$. In this hybrid the region from left of gene $N$ to some point beyond gene $P$ of $\lambda$ has been substituted by P22 DNA carrying 

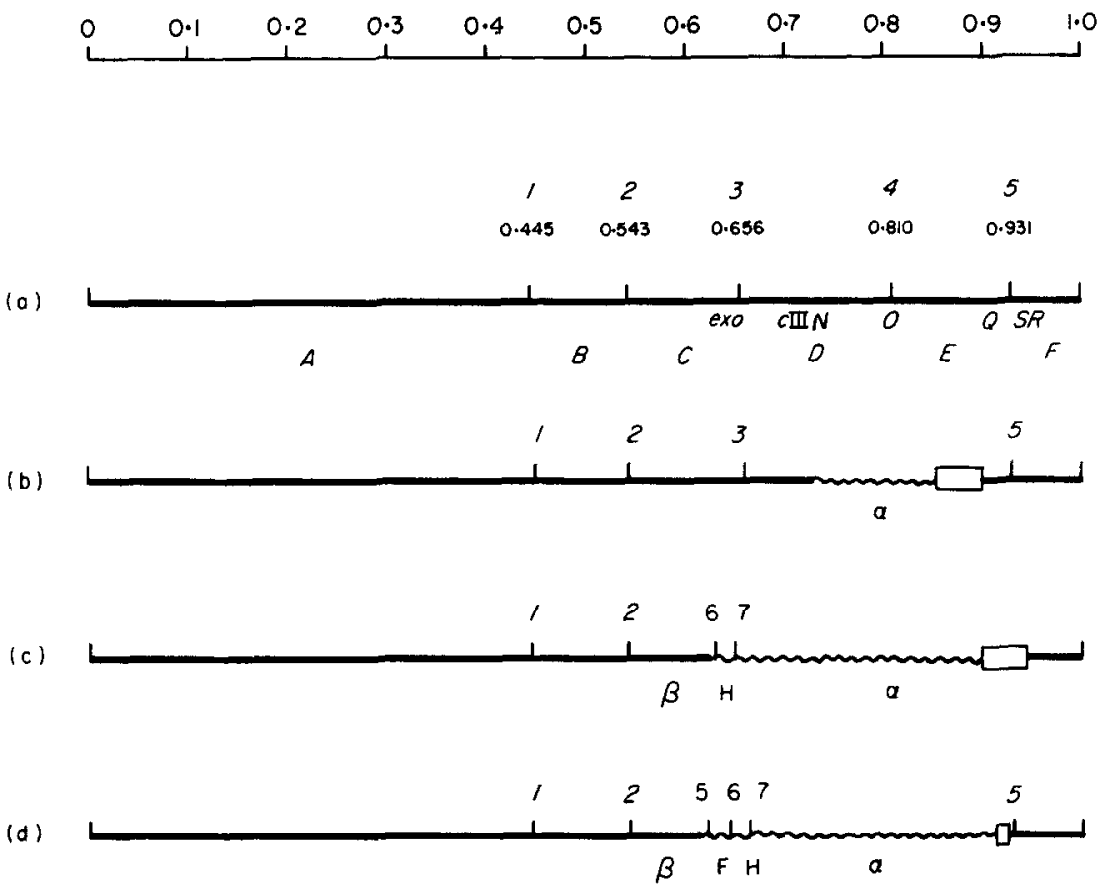

Fra. 4. EcoRI endonuclease cleavage site map of $\lambda$ and $\lambda i m m \mathrm{P} 22$ hybrid DNAs. Maps are shown to scale. Co-ordinates are fractional lengths of $\lambda$ DNA. (—- ), $\lambda$ sequences; ( P22 sequences. EcoRI cleavage sites are shown above each map. Letter designations for EcoRI generated fragments are shown below each map.

(a) EcoRI cleavage site map of $\lambda$ DNA. The physical locations of some $\lambda$ genes are given. (Redrawn from Thomas \& Davis, 1975).

(b) EcoRI cleavage site map of $\lambda i m m P 22 h y l$ DNA. The open bar in the map indicates the P22 substitution is shorter than the $\lambda$ DNA segment deleted. The position of the P22 substitution relative to the ends of $\lambda$ is from data given by Botstein \& Herskowitz (1974).

(c) EcoRI cleavage map of $\lambda$ imm P22hy38 DNA. The P22 substitution is shown as the minimum length consistent with the EcoRI fragments found. The open bar in the map indicates that the P22 substitution is shorter than the $\lambda$ deletion. The P22 substitution includes P22 EcoRI sites 6 and 7 (see Fig. 6).

(d) EcoRI cleavage map of $\lambda$ immP22hy37 DNA. The P22 substitution is shown as the minimum length consistent with the $E$ coRI fragments found. The open bar in the map indicates an unequal substitution. The P22 substitution includes P22 EcoRI sites 5, 6 and 7 (seo Fig. 6).

genes of analogous function. AimmP22hyl carries clII from the $\lambda$ parent. It is not known whether the hybrid carries $\lambda Q$ or a P22 analog. Analysis of heteroduplexes formed between $\lambda$ and $\lambda i m m$ P22hyl showed that the P22 substitution lies between 0.735 and 0.897 fractional lengths of $\lambda$ on the $\lambda$ physical map. The physical map of $\lambda$ immP22hyl is shown in Figure 4(b) aligned with the physical map of $\lambda$ showing the position of EcoRI cleavage sites in $\lambda$ DNA (Thomas \& Davis, 1975). To determine whether any EcoRI cleavage sites are located in the P22 substitution in $\lambda$ immP22hyl, the hybrid phage DNA was digested with $E c o$ RI and the cleavage products separated by electrophoresis through an agarose gel. The result is shown in Figure 1(c). Comparison with an $E c o R I$ digest of $\lambda$ shows that the hybrid yields $\lambda$ fragments $A, C, B$ and $F$, and lacks $\lambda$ fragments $D$ and $E$, as would be expected from inspection of the diagram in Figure 4 . Thus only $\lambda E$ coRI cleavage site 4 is replaced by the P22 sulstitution. The hybrid yields no P22 EcoRI fragment. The digest of the hybrid contains 
one new fragment not found in either the P22 or $\lambda$ parents. Since only one new fragment and no P22 fragment is found, there is no EcoKI cleavage site in the 122 DNA substitution. The new fragment must represent a fragment bounded by $\lambda$ EcoRI cleavage sites 3 and 5 . The molecular weight of the DNA between these two EcoRI sites in the $\lambda$ parent is $8.47 \times 10^{6}$ (Thomas \& Davis, 1975). A value of $7 \cdot 15 \times 10^{6}$ for the molecular weight of $\lambda i m m$ P22hyl fragment $\alpha$ was obtained by agarose gel electrophoresis as described previously. This value suggests that the length of the P22 substitution is slightly shorter than the $\lambda$ deletion.

The EcoRI analysis of $\lambda i m m P 22 h y 1$ shows that the P22 substitution in this hybrid contains no $E c o R I$ cleavage site. From the heteroduplex data given by Botstein \& Herskowitz (1974) we can calculate that the P22 substitution has a molecular weight of about $5 \times 10^{6}$. Since only P22 fragments $\mathrm{A}, \mathrm{B}$ and $\mathrm{C}$ have molecular weights equal to or greater than approximately $5 \times 10^{6}$, the P22 substitution found in $\lambda$ imm P22hyl must come from one of these three P22 EcoRI fragments.

\section{(e) EcoRI fragments of $\lambda$ imm P22hy38}

Since the P22 substitution in $\lambda$ imm P22hyl contained no EcoRI cleavage sites, a hybrid carrying a longer substitution was next studied. Genetic analysis has shown that the P22 substitution in $\lambda i m m \mathrm{P} 22$ hy38 includes the set of $\mathrm{P} 22$ genes present in $\lambda i m m \mathrm{P} 22 \mathrm{hy} 1$, and extends further to the right (S. Hilliker, personal communication). The positions of the endpoints of this substitution have not been determined and this hybrid has not been studied by heteroduplex analysis. Products of EcoRI cleavage of $\lambda$ immP22hy38 DNA are shown in Figure $\mathrm{l}(\mathrm{d})$. Fragments $A$ and $B$ are the only $\lambda$ fragments seen. Thus the P22 substitution replaces $\lambda E$ coRI cleavage sites 3, 4 and 5. One P22 fragment, $H$, is present. Two new fragments $\alpha$ and $\beta$ are found. The molecular weights of $\alpha\left(9.8 \times 10^{6}\right)$ and $\beta\left(2.65 \times 10^{6}\right)$ were determined from their electrophoretic mobility as described above (Table 1). Since the genetic evidence indicates that the P22 substitution of $\lambda$ immP22hyl of approximately $5 \times 10^{6}$ daltons is contained within the $\mathrm{P} 22$ region of $\lambda i m m \mathrm{P} 22 \mathrm{hy} 38$, the P22 region of $\lambda$ imm $\mathrm{P} 22 \mathrm{hyl}$ must lie within the new fragment $\alpha$ of $\lambda \mathrm{immP22hy38}$. The P22 substitution in $\lambda \mathrm{imm}$. P22hy38 extends further to the right than the dimmP22hyl substitution, since $\lambda i m m \mathrm{P} 22 \mathrm{hy} 38$ has substituted gene 13 of P22 for gene $S$ of $\lambda$. ( $\lambda$ immP22hyl has gene $S$ from the $\lambda$ parent, since it has $\lambda E c o R I$ fragment $F$.) Inspection of the position of $E c o$ RI cleavage sites relative to the $\lambda$ physical and genetic maps shows that the P22 substitution should cover $\lambda E c o$ RI site 5, as is found. A simple experiment demonstrated that fragment $\alpha$ of $\lambda$ immP22hy38 contains the right cohesive end of $\lambda$. If the EcoRI cleavage products of $\lambda i m m \mathrm{P} 22 \mathrm{hy} 38$ are incubated at $37^{\circ} \mathrm{C}$, and subsequently separated by electrophoresis, a band appears which migrates more slowly than $\lambda E c o$ RI fragment $A$ (Fig. 1(e)). This band was shown to represent a hydrogenbonded dimer. When the band was eluted from the gel, incubated at high temperature in low salt to disrupt the hydrogen-bonded cohesive end duplex, and again subjected to electrophoresis in agarose, $\lambda$ fragment $A$ and $\lambda$ imm P22hy38 fragment $\alpha$ reappeared.

The fragment pattern supports these conclusions. (1) $\lambda$ imm $\mathrm{P} 22$ hy38 fragment $\alpha$ includes the right cohesive end of $\lambda$. (2) The P22 substitution replaces $\lambda$ EcoRI cleavage sites 3, 4 and 5. (3) The P22 substitution introduces two P22 EcoRI cleavage sites; those which generate $\mathrm{P} 22$ fragment $\mathrm{H}$.

The fragment map of the $\lambda$ immP22hy38 hybrid which conforms with these conclusions is shown in Figure 4(c). A minimum size for the P22 component of fragment 
$\alpha$ can be estimated. The P22 material extends from the left end of fragment $\alpha$ to a distance from the right cohesive end which is less than the length of $\lambda E c o R I$ fragment $F$. The molecular weight of $\alpha$ is estimated as $9.8 \times 10^{6}$ and the molecular weight of $\lambda F$ is $2 \cdot 13 \times 10^{6}$. Therefore the molecular weight of the P22 sequences in $\alpha$ is a minimum of about $7.7 \times 10^{6}$ and a maximum of about $9 \cdot 8 \times 10^{6}$. This length of P22 DNA contains no EcoRI cleavage site. It must therefore correspond to sequences included in EcoRI fragment A of P22, which is the only P22 fragment large enough to include DNA with $M_{\mathrm{r}}=7.7 \times 10^{6}$ having no $E c 0 \mathrm{RI}$ cleavage site. It is thus also possible to conclude that the P22 sequences in $\lambda i m m \mathrm{P} 22$ hyl are derived from P22 EcoRI fragment A, rather than fragment B or C. Finally, the גimm P22hy38 map shows that fragment $H$ is adjacent to fragment $A$ in P22, as shown in Figure 4(c).

\section{(f) EcoRI fragments of גimmP22hy37}

The phenotype of $\lambda i m m$ P22hy37 suggested that the P22 substitution in this hybrid extends further to the left than the $\mathrm{P} 22$ regions in the two hybrids described previously. Hybrid גimmP22hy37 has a $s p i^{-}$phenotype, while the other two hybrids are $s p i^{+}$ (Zissler et al., 1971). The spi- phenotype is characteristic of mutants of $\lambda$ in which recombination functions are defective. The $E c o R I$ cleavage products of $\lambda i m m P 22 h y 37$ DNA are shown in Figure $\mathbf{l}(\mathbf{f})$. The hybrid yields $\lambda$ fragments $A, B$ and $F$, and so retains $\lambda E$ coRI sites 1,2 and 5. The P22 substitution replaces $\lambda E c o R I$ sites 3 and 4. P22 fragments $F$ and $H$ are present. The two fragments not present in either the $\lambda$ or P22 parents are designated $\alpha$ and $\beta$ (Fig. 1(f)). Consideration of these data, together with the fragment maps of $\lambda$ and $\lambda$ immP22hy38 generates the fragment map for $\lambda$ immP22hy37 shown in Figure 4(d). This map yields the partial P22 fragment

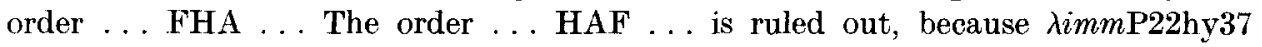
retains $\lambda$ EcoRI site 5, and thus the P22 substitution does not extend as far to the right as $\lambda$ immP22hy38, which does not retain $\lambda$ EcoRI site 5 .

\section{(g) EcoRI fragments of a P22 deletion mutant}

Most P22 late genes have not been inserted into a $\lambda$ chromosome, so EcoRI sites in the late region cannot be mapped in hybrids. The partial fragment map of P22 was therefore extended by study of a deletion mutant of P22. Heteroduplex analysis shows that $14 \%$ of the chromosome has been deleted in P22 bp5 (Tye et al., 1974a). The EcoRI cleavage products of P22 bp5 are shown in Figure 5(a). Comparison of the P22 bp5 fragments with the P22 digest shows that the bp5 deletion has resulted in the loss of P22 EcoRI fragments C, F, G and H. (The disappearance of the diffuse leading edge of band $\mathrm{A}$ in bp5 results from alterations in the position of maturation cleavages occurring during packaging of DNA into phage heads and has no significance for the mapping of EcoRI cleavage sites. A more complete analysis of the P22 bp5 fragments is presented elsewhere (Jackson et al., 1978)).

Since a single deletion has affected fragments C, F, G and $H$, these fragments must be contiguous in the P22 chromosome. Since the partial P22 fragment order ... FHA ... has been established from study of the $\lambda$ immP22 hybrids, two alternative partial orders fulfil the requirement that $C, F, G$ and $H$ be adjacent: ... CGFHA ... or ... GCFHA ... That ... CGFHA ... is correst is established by considering that fragment $\mathrm{C}$ represents $17 \%$ of the $\mathrm{P} 22$ chromosome. Thus a $14 \%$ deletion could not affect all four fragments in the order . . GCFH . . . Therefore 
(a)

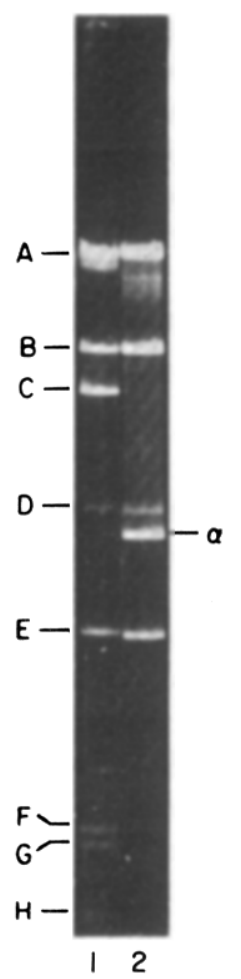

(b)

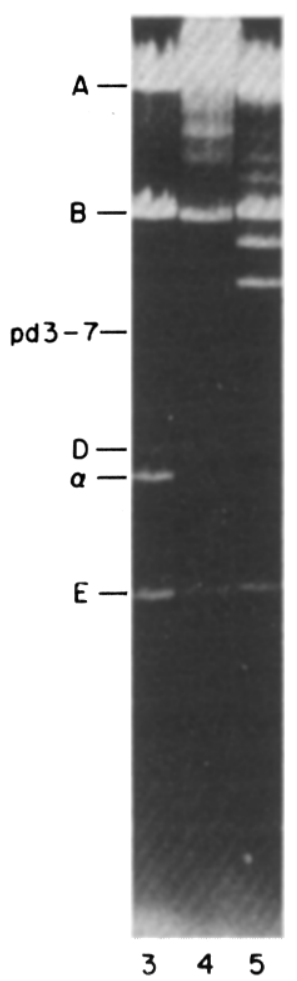

(c)

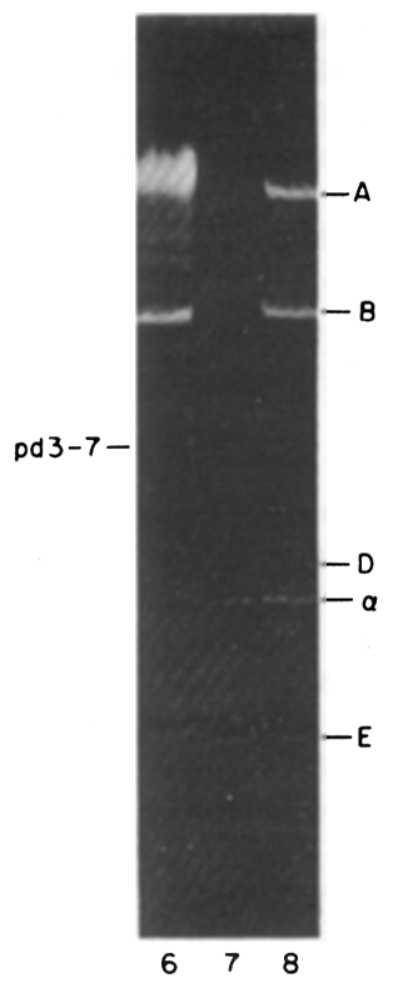

Frg. 5. EcoRI endonuclease cleavage products of P22 bp5 DNA.

(a) EcoRI digestion products of P22 DNA (gel 1) and P22 bp5 DNA (gel 2) in which 14 to $16 \%$ of the P22 chromosome is deleted.

(b) Fragments produced by complete EcoRI cleavage (gel 3) of P22 bp5 DNA compared with products of partial EcoRI cleavage of P22 bp5 DNA (gel 4) and P22 DNA (gel 5).

(c) The fragment pd 3-7 produced by incomplete EcoRI cleavage of P22 bp5 DNA (gel 6) was separated from the other fragments, cleaved with excess $E c o R I$, and the products separated by electrophoresis (gel 7). A limit digest of P22 bp5 DNA run in parallel is included for comparison (gel 8).

Conditions for partial digestion and for purification of pd 37 are described in Matorials and Methods.

the correct partial order of P22 fragments is ... CGFHA ... . The new fragment seen in the bp5 digest therefore is a fusion of part of $\mathrm{C}$ with part of $\mathrm{H}$.

\section{(h) EcoRI fragment map of $P 22$}

Analysis of $\lambda i m m \mathrm{P} 22$ hybrid phages and a P22 deletion mutant has yielded the partial fragment map of ... CGFHA .... The two P22 fragments B and E which have not yet been ordered on the map are not incorporated in any known hybrid or altered in any deletion mutant. These fragments were ordered by partial digestion of P22 bp5 DNA with EcoRI.

In P22 bp5 the deletion removes part of $\mathrm{C}$, all of $\mathrm{G}$ and $\mathrm{F}$, and part of $\mathrm{H}$. The deletion fuses a segment of fragment $\mathrm{C}$ to a segment of fragment $\mathrm{H}$ to produce a 
new fragment of molecular weight $2.4 \times 10^{6}$ designated $\alpha$ (Fig. 5(a)). It was experimentally more convenient to use P22 bp5 DNA as a substrate for partial digestion with $E c o$ RI to order E and B with respect to $\alpha$, instead of using wild-type P22 DNA partial digests (to order $\mathrm{F}$ and $\mathrm{B}$ with respect to $\mathrm{C}$ ). Since $\alpha$ is present in P22 bp5 but not in P22, a fragment which appears among products of partial digestion of P22 bp5 but not P22 will include $\alpha$. Thus the fragment EcoRI pd 3-7 in Figure 5(b), which is found only in the P22 bp5 partial digest, must include $\alpha$. The predicted molecular weights for the fragments corresponding to each of the two alternative fragment orders . . BE $\alpha \ldots$ or . . EB $\alpha \ldots$ are, respectively, $4 \cdot 0 \times 10^{6}(\mathrm{E} \alpha)$ or $8.5 \times 10^{6}(\mathrm{~B} \alpha)$. The partial product pd 3-7 in Figure $5(\mathrm{~b})$ migrates significantly faster than fragment $\mathrm{B}$ in the same gel, suggesting that the order $\mathrm{E} \alpha$ is correct. The partial digestion product pd 3-7 was purified and cleaved with EcoRI and the products separated by electrophoresis through an agarose gel. Figure 5(c) shows that complete digestion of the partial product pd 3-7 yields P22 bp5 EcoRI fragments $\alpha$ and E. Therefore the correct order of P22 bp5 $E$ coRI fragments is . . BExA . . , which corresponds to the P22 fragment order . . BECGFHA . . . Since P22 linear chromosomes are a set of circular permutations, the fragment map must be circular. That EcoRI fragments B and E are adjacent in intact P22 chromosomes was confirmed directly by analysis of HindIII fragments of P22 DNA (R. J. Deans, unpublished experiments). The complete order of P22 EcoRI fragments is shown in the circular fragment map in Figure 6.

\section{(i) Orientation of $P 22$ Eco $R I$ fragment map with the genetic map}

Some P22 genes can be located on the P22 EcoRI fragment map by considering the genetic composition of the three $\lambda$ imm P22 hybrids together with the EcoRI cleavage maps shown in Figures 4 and 6 . The P22 substitution in $\lambda$ immP22hyl has been shown to include P22 genes 24,c2, 18 , and 12 (Fig. 4(b); Botstein \& Herskowitz, 1974). The larger P22 substitution in $\lambda$ imm P22hy38 is known to include all the P22 genes present in $\lambda$ immP22hyl and P22 gene 13 as well (S. Hilliker, personal communication). We have shown that the P22 component of $\lambda$ immP22hy38 EcoRI fragment $\alpha$ is derived from P22 EcoRI fragment A. Since all P22 sequences in $\lambda i m m$ P22hyl are included in $\lambda$ immP22hy38 fragment $\alpha$, the P22 genes $24, c 2,18,12,23$, 13 must be located on P22 EcoRI A. Inspection of the גimmP22hyl and גimmP22hy38 maps (Fig. 4(b) and (c)) shows that this block of P22 genes is oriented on P22 EcoRI. A with gene 24 nearer P22 EcoRI cleavage site 7 (Fig. 6).

Our data do not allow us to map precisely the physical location of genes within P22 fragment A. However, some conclusions about physical location of the early genes relative to EcoRI cleavage sites can be made. If $\lambda$ immP22hy38 fragment $\alpha$ were composed entirely of $\mathrm{P} 22$ sequences (and it is not, since it has the $\lambda$ right cohesive end), גimmP22hy38 $\alpha$ would contain $15 \times 10^{3}$ base-pairs of P22 DNA. Gene 13 is on $\alpha$, so gene 13 is a maximum of $15 \times 10^{3}$ base-pairs or $36 \%$ P22 from P22 EcoRI site 7 . By analogous arguments, the maximum size of the P22 component of $\lambda \mathrm{immP} 22 \mathrm{hy} 37$ fragment $\alpha$ is $11 \times 10^{3}$ base-pairs. Since P22 genes 18 and 12 are on $\lambda$ imm $\mathrm{P} 22$ hy $37 \alpha$, they are separated from $\mathrm{P} 22$ site 7 by a maximum of $11 \times 10^{3}$ base-pairs.

EcoRI analysis of P22 bp5 allows some other early genes to be assigned to EcoRI fragments. We have used $E c o R I$ cleavage to study several P22 deletion and insertion mutants which were previously studied by heteroduplex analysis in the electron microscope (Tye et al., 1974a,b; Chan, 1974; Chan \& Botstein, 1976). When the 


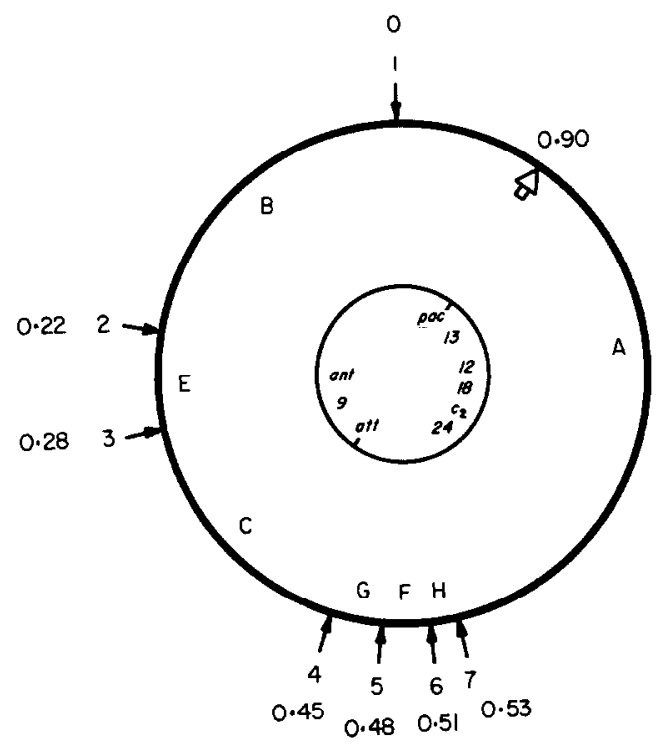

Fig. 6. EcoRI endonuclease cleavage map of the P22 chromosome. The cleavage map is shown to scale. EcoRI cleavage sites are marked by arrows and numbered counterclockwise. The coordinates of the EcoRI cleavage sites are fractions of the length of unique P22 DNA $\left(M_{\mathrm{r}}=\right.$ $27.45 \times 10^{6}$; unique P22 DNA is mature P22 DNA molecules less the $3 \%$ terminal redundancy). The EcoRI-generated fragments of P22 DNA are designated by capital letters. The open arrow indicates the physical location of pac, the site at which P22 DNA packaging begins (Jackson et al., 1978). The inner circle shows the assignment of some P22 genes to EcoRI fragments. att is located at 0.40 and pac at $\mathbf{0 . 9 0}$ on the physical gene map. Positions of other genes within a fragment are not to scale.

int lies between att and EcoRI site 7, and erf is located beyond EcoRI site 6 in the counterclockwise direction (not shown).

EcoRI cleavage maps are aligned with the map of Chan \& Botstein (1976) showing physical location of some P22 genes, the following conclusions could be made. The P22 prophage attachment site is located in fragment C. P22 gene erf is located either on $\mathrm{H}$ or $\mathrm{A}$. Gene int lies between sites 3 and 7 and cannot be located on A. These results are presented in detail in the accompanying paper (Jackson et al., 1978).

The orientation of the P22 genetic map relative to the P22 EcoRI fragment map is shown in Figure 6. Since no dimmP22 hybrids or P22 insertion or deletion mutants are known which provide physical markers near P22 late genes, our data do not permit assignment of head and tail genes to particular EcoRI fragments.

\section{Discussion}

(a) EcoRI cleavage map of P22 DNA

$E c o$ RI cleavage sites on the chromosome of bacteriophage P22 have been ordered by comparing products of EcoRI cleavage of P22 DNA, $\lambda$ DNA, DNAs of three גimmP22 hybrid phages and DNA of a P22 deletion mutant. The positions of the $E c o$ RI cleavage sites in these mutant phages were determined by estimating the molecular weights of the corresponding fragments from their electrophoretic mobilities in agarose gels. When the fragments obtained from the mutants were compared with 
the EcoRI fragments of the P22 and $\lambda$ parents, the order of EcoRI cleavage sites in P22 could be deduced.

In these experiments the P22 DNA cleaved with EcoRI was the mature form isolated from phage particles. Since these linear P22 DNA molecules are circularly permuted, the cleavage map is a circle (Fig. 6). Although EcoRI digestion of linear P22 wild-type DNA yields eight bands after electrophoresis in agarose gels, one of these (band D) contains a segment of EcoRI fragment A from the end of a linear DNA molecule (Jackson et al., 1978). Thus, although the P22 DNA substrate was linear, and digests yielded eight bands after electrophoresis, there are seven $E c o$ RI cleavage sites in P22 DNA and the seven DNA fragments with EcoRI termini at both ends define a circular map of P22 DNA.

\section{(b) Correlation of EcoRI cleavage map with the P22 genetic map}

Use of the גimmP22 hybrids and the P22 bp5 deletion mutant allowed us to assign some genes to P22 EcoRI fragments. Some of the P22 genes included in the P22 substitutions in the three $\lambda$ immP22 hybrids have been identified (Botstein \& Herskowitz, 1974; S. Hilliker, personal communication). Similarly, some P22 genes were known to be deleted in P22 bp5, and other genes were located in reference to the position of the P22 bp5 deletion (Chan, 1974; Chan \& Botstein, 1976). The positions of P22 EcoRI sites in these phages could therefore be correlated with the physical locations of some P22 genes. In this way, the P22 EcoRI cleavage map was shown to be oriented with the P22 genetic map as shown in Figure 6. P22 genes 24 through 13 lie between sites 7 and 1. Thus all essential control and DNA replication genes of P22 are located on P22 EcoRI A. The P22 attachment site is located on fragment $\mathrm{C}$, and the $\mathrm{P} 22$ essential recombination function (erf) is encoded on either fragment $\mathrm{H}$ or on A near site 7. The gene specifying the antirepressor (ant) is located between EcoRI sites 2 and 3 , and gene 9 (tail gene) is located on fragment $\mathrm{C}$ between EcoRI site 3 and att (G. Weinstock and D. Botstein, unpublished experiments). Some late genes are included on fragment A near site 1 (e.g. gene 13), and we expect that most of the head genes will be found to lie on fragment $B$. These results are the first steps toward mapping the physical location of genes on the P22 chromosome. Work is in progress in this laboratory to generate a more detailed P22 physical gene map.

The recombination frequencies between $\lambda$ genes are in general proportional to molecular distances between markers (Davidson \& Szybalski, 1971). However, it is likely that the P22 physical gene map will show that some distances between genes on the P22 genetic map are greatly distorted. The genes $3,2,1,8$ and 5 (genes for functions required in DNA maturation and head assembly which lie between genes 13 and ant) occupy almost one-half of the $\mathrm{P} 22$ recombination frequency map (Botstein et al., 1972). Yet the sum of the molecular weights of the polypeptide products of these five genes would require only $10 \%$ of the coding capacity of the P22 genome. Most likely there are not a large number of genes yet to be discovered between gene: 3 and 5 . All genes required for phage particle assembly have probably been identified (Botstein et al., 1973; Poteete \& King, 1977) and, since genes of similar function are clustered in P22, no new gene would be expected to be found in this region. Therefore either there are long stretches of non-essential DNA between genes $3,2,1,8$ and 5 or recombination frequencies in this region are a poor measure of physical distance along the chromosome. We favor the latter explanation. Molecular ends of P22 
mature chromosomes cleaved during headful packaging fall in this region of the map (Jackson et al., 1978). The ends of the molecules may distort recombination frequencies in this part of the map.

\section{(c) Alignment of $\lambda$ and P22 EcoRI physical maps}

The P22 genetic map shows that P22 genes governing integration, recombination, phage repressor synthesis, DNA synthesis and cell lysis, have the same order as the $\lambda$ genes of analogous function which lie in the right arm of $\lambda$ (Botstein et al., 1972). Comparison of the physical maps shows that this region is the same size in both phages (Fig. 7). A DNA molecule including one complete and unique set of P22 genes is $89 \%$ the size of the $\lambda$ chromosome. In Figure 7 , both $\lambda$ and P22 fragment lengths are plotted as fractions of the length of a $\lambda$ DNA molecule. The P22 circular map was split at the position of pac, the packaging initiation site (Jackson et al., 1978). Since the P22 fragment map is shorter than the $\lambda$ map, the two maps are aligned at the position of the prophage attachment sites. This site has been located on the physical maps of both phages (Chan, 1974; Davidson \& Szybalski, 1971; Jackson et al., 1978). When the maps are aligned by the att sites, the right arms of the two phages are about the same length and the left arm of P22 is shorter than the $\lambda$ left arm. This linear representation of the P22 EcoRI cleavage site map is also a map of the mature linear P22 chromosomes which are encapsulated in a headful initiating at pac (terminal redundancy not shown; Jackson et al., 1978).

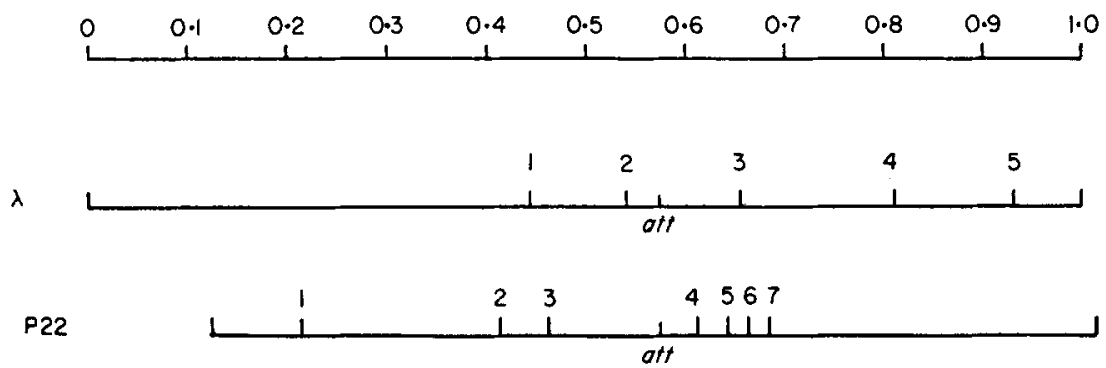

FIG. 7. Alignment of P22 and $\lambda$ EcoRI fragment maps. The P22 EcoRI cleavage map is drawn as a linear map and the physical co-ordinates altered for comparison with the $\lambda E$ coRI cleavage map. The circular EcoRI fragment map of P22 DNA (Fig. 6) was broken at the site at which P22 DNA packaging begins to give a linear map that corresponds to the first DNA molecule cut in a headful packaging sequence (Jackson et al, 1978). Length of P22 EcoRI fragments is plotted as fractional length of $\lambda$ DNA. The P22 and $\lambda$ fragment maps are aligned at the att sites.

\section{(d) $\lambda \mathrm{imm} P 22 h y 38$ as a vector for insertion of foreign $D N A$}

The alignment of P22 and $\lambda$ physical maps (Fig. 7) and the location of P22 and $\lambda$ genes on the EcoRI fragments of $\lambda i m m P 22 h y 38$ (Fig. 4) suggest that this hybrid phage could be used as a vector into which foreign DNA could be inserted and then replicated. All the essential genes which code for proteins of the $\lambda$ head and tail are on fragment A. The essential DNA synthesis and regulatory genes derived from the P22 parent are located on fragment $\alpha$. Therefore $\lambda$ immP22hy38 EcoRI fragments $A$ and $\alpha$ include all genes necessary for lytic growth. It should be possible to insert foreign DNA in place of fragments $B, \beta$ and $H$. This hybrid therefore would be analogous to $\lambda$ vectors described previously (Thomas et al., 1974; Murray \& Murray, 
1974; Rambach \& Tiollais, 1974). It differs from these $\lambda$ vectors in having P22specific regulatory functions and early genes and the promoter $\mathrm{P}_{\mathrm{L}}$ derived from $\mathrm{P} 22$.

We thank Myron Levine, who introduced us to P22 and in whose laboratory these (xperiments were begun. All $\lambda i m m P 22$ hybrids used in this work were generously supplied by David Botstein and Sandra Hilliker. David Jackson performed the electron microseopy. We thank John Voorhees for access to the electron microscope. We are grateful to Tony Weighous for expert assistance with some of the later experiments, and to Robert Deans for discussion and access to unpublished results. David Jackson, William Folk, Myron Levine and David Friedman provided valuable discussion and criticism of the manuscript. This work was supported by a grant from the National Institutes of Health (grant no. AT-12369).

\section{REFERENCES}

Botstein, D. \& Herskowitz, I. (1974). Nature (London), 251, 584-589.

Botstein, D., Chan, R. K. \& Waddell, C. H. (1972). Virology, 49, 268-282.

Botstein, D., Waddell, C. \& King, J. (1973). J. Mol. Biol. 80, 669-695.

Chan, R. K. (1974). Ph.D. thesis, Massachusetts Institute of Technology.

Chan, R. K. \& Botstein, D. (1976). Genetics, 83, 433-458.

Collins, C. J., Jackson, D. A. \& DeVries, F. A. J. (1976). Proc. Nat. Acad. Sci., U.S.A. $73,3838 \quad 3842$.

Davidson, N. \& Szybalski, W. (1971). In The Bacteriophage Lambda (Hershey, A. D., ed.), pp. 45-82, Cold Spring Harbor Press, New York.

Davis, R. W., Simon, M. N. \& Davidson, N. (1971). Methods Enzymol. 21, 413-428.

Hedgpeth, J., Goodman, H. M. \& Boyer, H. W. (1972). Proc. Nat. Acad. Sci., U.S.A. 69, 3448-3452.

Helling, R. B., Goodman, H. M. \& Boyer, H. W. (1974). J. Virol. 14, 1235-1244.

Jackson, E. N., Jackson, D. A. \& Deans, R. J. (1978). J. Mol. Biol. 118, 365-388.

Lai, C. J. \& Nathans, N. (1974). J. Mol. Biol. 89, 179-193.

Murray, N. E. \& Murray, K. (1974). Nature (London), 251, 476 481.

Poteete, A. R. \& King, J. (1977). Virology, 76, 725-739.

Rambach, A. \& Tiollais, P. (1974). Proc. Nat. Acad. Sci., U.S.A. 71, 3927-3930.

Rhoades, M., MacHattic, L. A. \& Thomas, C. A. Jr. (1968). J. Mol. Biol. 37, 2140.

Smith, H. O. \& Nathans, D. (1973). J. Mol. Biol. 81, 419-423.

Thomas, M. \&. Davis, R. W. (1975). .J. Mol. Biol. 91, 315-328.

Thomas, M., Cameron, .J. R. \& Davis, R. W. (1974). Proc. Nat. Acad. Sci, U.S.A. 71. $4579-4583$.

Tye, B. K., Chan, R. K. \& Botstein, D. (1974a). J. Mol. Biol. 85, 485-500.

Tye, B. K., Huberman, J. A. \& Botstein, D. (1974b). J. Mol. Biol. 85, 501-532.

Weaver, S. \& Levine, M. (1978). J. Mol. Biol. 118, 389-411.

Zissler, J., Signer, E. \& Schaefer, F. (1971). In The Bacteriophage Lambda (Hershey, A. D.. ad.), pp. 469-476, Cold Spring Harbor Press, New York. 